\title{
Material Selection of Natural Fibre Using a Grey Relational Analysis (GRA) Approach
}

\author{
Nurul Ain Maidin, ${ }^{\mathrm{a}, \mathrm{b}}$ S. M. Sapuan, ${ }^{\mathrm{a}, *}$ Mastura Mohammad Taha, ${ }^{\mathrm{b}}$ and Mohd Zuhri \\ Mohamed Yusoff ${ }^{\text {a }}$
}

\begin{abstract}
Numerous situations in daily life necessitate a decision. Several of them entail selecting the best option from a number of available options. In many such cases, no single solution is optimal for all of the performance characteristics. This study proposes using grey relational analysis (GRA), a multiple criteria decision making (MCDM) method, to solve this problem. Material selection is vital in designing and developing products, especially for composites materials requiring special attention. The substitution of conventional materials with natural fibres as base material is commonly practised due to high material consumption in mass-producing plastic components that could harm the environment. Therefore, in this work, natural fibres were chosen as composite reinforcement in the design of cyclist helmets. This approach was used to evaluate the right natural fibre and is able to fulfil the needs of consumers and the environment. From the results, the GRA method was utilised and revealed that pineapple was the best top ranking natural fibre with a grade of 0.5687 , followed closely by bamboo with a grade of 0.5678 , and abaca with a grade of 0.4966 . Error analysis was performed to increase the confidence level of the results obtained.
\end{abstract}

DOI: 10.15376/biores.17.1.109-131

Keywords: Natural fibre; Material selection; Grey relational analysis (GRA); Multiple criteria decision making (MCDM); Cyclist helmets

Contact information: a: Department of Mechanical and Manufacturing Engineering, Faculty of Engineering, Universiti Putra Malaysia (UPM), 43400 UPM Serdang, Selangor Darul Ehsan, Malaysia; b: Department of Manufacturing Engineering Technology, Faculty of Mechanical and Manufacturing Engineering Technology, Universiti Teknikal Malaysia Melaka (UTeM), 76100 Durian Tunggal, Melaka, Malaysia;

* Corresponding author: sapuan@upm.edu.my

\section{INTRODUCTION}

Natural fibres include agricultural biomass, which can substantially support a country's environmental policy while also contributing to the economy. The broad usage and accessibility of such natural fibres can assist in alleviating pressure on forests and agriculture. Using raw materials from various natural fibres will help maintain the ecological balance of nature (Pimenta and Pinho 2011). Natural fibre reinforcements in composites have the advantages of being lightweight, easily available, low cost, nonabrasive, recyclable, low $\mathrm{CO}_{2}$ emitting, biodegradable, and renewable. Individual and intrinsic physical, mechanical, and distinctive surface qualities exist in natural fibres derived from the stalks, leaves, stems, fruits, and seeds of plants. To develop unique composites, a vast understanding of the unique characteristics of natural fibres and their blends is essential. The qualities of fibre, with a significant effort and technologies to select 
a set of machinery and machine parameters and ways for blending natural fibres, will result in a well-matched product at the lowest practical cost (Zakriya and Ramakrishnan 2021). According to Grand View Research (2018), natural fibre composites provide advantages such as lower density, better thermal and sound insulation, electrical insulation, and good mechanical qualities, which favour the functional application of composites. Natural fibre composites have the potential to be favorable ways to address aspects of the industry's negative environmental impact. The production and disposal of natural fibres from agricultural waste have massive potential in a tropical agricultural context. Natural fibres are valuable by-products of the extraction process and can be used to reinforce composite goods. Natural fibres reinforcement in composite materials give stiffness and adequate strength and contribute to the materials' distinctive features (Johansson et al. 2012; Puglia et al. 2005; Al-Oqla et al. 2015; Sanyang et al. 2016). The reinforcement also results in a decreased density, high specific characteristics, excellent thermal properties, and excellent fracture resistance (Cheung et al. 2009; Majeed et al. 2013; Salit 2014a, 2014b). Natural fibres are ideal options for high-quality reinforcement in composite materials because of these characteristics (Mitra 2014; Al-Oqla and Omari 2017).

Ju-long Deng of Huazhong University of Science and Technology invented grey relational analysis (GRA), which is also known as grey incidence analysis (Deng 1989). It is one of the most extensively utilised grey system theory models. Grey relational analysis, according to Deng (1989), employs a unique understanding of information. For the problem in material selection, the MCDM procedure can be simple. Grey relational analysis is widely utilised in Asia, according to Chan and Tong (2007). It is an effective evaluation methodology that uses the grade of relation to determine the similarity or difference degree between two sequences. The GRA benefits from point-set topology, which allows for a global comparison of two data sets rather than a local comparison based on measuring two locations' distance. As a result, it eliminates the undesirable aftereffect of subjective parameter setting within the model. According to Wang et al. (2013), many past researchers have proposed some methods for solving MCDM problems, including scoring models proposed by Nelson (1986), simple additive weighting proposed by Yoon and Hwang (1995), axiomatic design proposed by Kulak (2005), analytic hierarchy process (AHP) proposed by Pohekar and Ramachandran (2004), and axiomatic design proposed by Kulak and Kahraman (2005). Almost all of the methods discussed above rely on weights to determine the corresponding value of each criterion. According to Yurdakul and Tansel (2009), the outcome is susceptible to weight changes, e.g., different weights generate varied results. When a decision making (DM's) weight changes, process repetition of the whole mathematical calculation is essential, which may be impractical and ineffective for DMs with limited mathematics abilities. Grey system theory is a mathematical tool for dealing with imperfect, partial, and ambiguous data. Deng (1989) was the first to use it to investigate the uncertainties in system models to aid prediction and decision-making.

Many studies on material process selection have been performed in the past for composites product development and product design. Mastura et al. (2018) published a novel study on selecting thermoplastic polymers for natural fibre-reinforced polymer composites for car anti-roll bars. The quality function deployment for environment (QFDE) technique was used to determine the best thermoplastic polymer. On the other hand, Salwa et al. (2019) investigated the system for material selection of natural fibres as biopolymer composites reinforcement for food packaging application. The process used the analytic 
hierarchy process (AHP) approach to determine the most suited natural fibre reinforcement.

Generally, in previous studies on material selection in various applications, multiple-criteria approaches have been widely used. It is relatively uncommon to find similar studies for biocomposite material selection for consumer products application, such as cyclist helmets, from the literature. Bharath and Basavarajappa (2016) and Bharath et al. (2018) reviewed the applications of natural fibres biocomposite materials originating from renewable resources, which highlighted the performed effort of using coir-polyester composites to manufacture helmets. In 2018, Bharath et al. demonstrated the fabrication process and mechanical characterisation of biocomposite helmets. These two are among the limited recent studies on biocomposites helmet application. To the best of the authors' knowledge, there has been no natural fibre utilisation as a reinforcing element in biocomposites, particularly for cyclist helmet design applications. Thus, a straightforward and systematic method selection would be helpful to aid designers and material engineers in the selection process. A model based on grey relational sequence generation, a wellknown GRA method, is proposed in this work for the selection of the best natural fibre as reinforcement in biocomposites for cyclist helmet application.

\section{EXPERIMENTAL}

\section{Gray Relational Analysis}

Deng (1982) proposed the grey system theory that is broadly applicable to various fields. This theory has been shown to aid the processing of uncertain, incomplete, and imperfect information. Grey relational analysis is a branch of grey system theory that may be used to solve complex interrelationships among multiple variables and factors as claimed by Moran et al. (2006). Grey relational analysis is an impact assessment model that uses the grade of relation to measure the similarity between the comparability and reference sequences. The study employed the Microsoft Excel 2016 software for calculation (Microsoft, Redmond, WA, USA). The GRA method has four main steps. The primary step is the grey relational sequence generation that comprises comparability sequence construction based on the attributes for all alternatives. After transmuting all performance attributes into a single comparability sequence, an ideal target or reference sequence, which is comparable to the created grey relational sequence, is well-defined. The grey relational coefficient is then computed for all attributes. The last step is the determination of the grey relational grade (GRG) of the computed coefficients and weights accredited to the attributes of performance. The obtained GRG is used to rank the alternatives (Geum et al. 2011; Jayakrishna and Vinodh 2017). Figure 1 is the GRA flow and structure employed in this study for the selection process of natural fibre as a reinforcement in biocomposites for cyclist helmets.

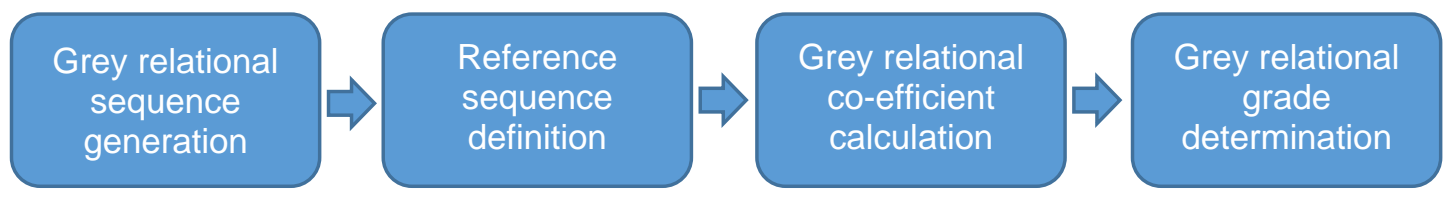

Fig. 1. GRA procedure 


\section{Step 1. Grey relational sequence generation}

In the multi-criteria problem, the decision matrix was expressed using sets of alternatives as well as the attributes' performance values. The generation of the grey relational sequence consists of normalising the decision matrix, forming the attributes' comparability sequence (Geum et al. 2011; Jayakrishna and Vinodh 2017). For instance, if the decision matrix comprised $m$ alternatives and $n$ attributes, the performance value was expressed as shown in the following formula,

$$
Y_{i}=\left(y_{i 1}, y_{i 2}, \ldots y_{i j}, \ldots, y_{i n}\right)
$$

where $y_{i j}$ performance values of attribute $j$ of alternative $i$.

The term $Y_{i}$ can be normalised into a comparability sequence $X_{i}=\left(x_{i 1}, x_{i 2}, \ldots x_{i j}, \ldots\right.$, $\left.x_{i n}\right)$ using the following equations:

$$
\begin{aligned}
& x_{i j}= \\
& \frac{y_{i j}-\min \left\{y_{i j}, i=1,2, \ldots, m\right\}}{\max \left\{y_{i j}, i=1,2, \ldots, m\right\}-\min \left\{y_{i j}, i=1,2, \ldots, m\right\}} \text { for } i=1,2, \ldots, m ; j=1,2, \ldots, n \\
& x_{i j}= \\
& \frac{\max \left\{y_{i j}, i=1,2, \ldots, m\right\}-y_{i j}}{\max \left\{y_{i j}, i=1,2, \ldots, m\right\}-\min \left\{y_{i j}, i=1,2, \ldots, m\right\}} \text { for } i=1,2, \ldots, m ; j=1,2, \ldots, n
\end{aligned}
$$

Eq. 1 was used if the performance attribute desired value was larger, and Eq. 2 was used in case the attribute desired value was smaller.

\section{Step 2. Derivation of the reference sequence}

The comparability sequence values, $X_{i}$ was scaled into the $[0,1]$ range after the generation of grey relational sequence. Better performance was shown by the alternative with the larger value of $X_{i}$ (equal to unity), a condition that usually does not exist. Thus, a reference sequence, $X_{0}$ that values equal to 1 was defined and compared with the generated sequence. The option having the higher similarity degree was the better alternative. The reference sequence was expressed as follows:

$$
X_{0}=\left(x_{01}, x_{02}, \ldots, x_{0 j}, \ldots, x_{0 n}\right)=(1,1, \ldots, 1 \ldots, 1)
$$

\section{Step 3. Calculation of grey relational coefficient}

The grey relational coefficient determined the degree of similarity between ${ }^{x_{0 j}}$ and $x_{i j}$. The grey coefficient value between $x_{0 j}$ and ${ }^{x_{i j}}$ can be computed using Eq. 3,

$$
\gamma\left(x_{0 j}, x_{i j}\right)=\frac{\Delta_{\min }+\delta \Delta_{\max }}{\Delta_{i j}+\delta \Delta_{\max }}
$$

where $\Delta_{i j}=\left|x_{0 j}-x_{i j}\right|$

$$
\begin{aligned}
& \Delta_{\text {min }}=\min \left\{\Delta_{i j}, i=1,2, \ldots, m ; j=1,2, \ldots, \mathrm{n}\right\} \\
& \Delta_{\text {max }}=\max \left\{\Delta_{i j}, i=1,2, \ldots, m ; j=1,2, \ldots, \mathrm{n}\right\}
\end{aligned}
$$




$$
\delta=\text { distinguishing coefficient, } \delta \in[0,1]
$$

The distinguishing coefficient was determined by the decision-maker, and different distinguishing coefficients gave varied GRA results. In this study, the distinguishing coefficient was assumed to be 0.5 .

Step 4. Calculation of GRG

Determination of the correlation level between the reference and comparability sequences was made using the GRG and could be computed using Eq. 4,

$$
\Gamma\left(X_{0}, X_{i}\right)=\sum_{j=1}^{n} W_{j} \gamma\left(x_{0 j}, x_{i j}\right)
$$

where $w_{j}$ is the weight assigned to the attribute $j$.

The total weight assigned to the attributes is unity, i.e.,

$$
\sum_{j=1}^{n} W_{j}=1
$$

The reference sequence indicates the utmost level of performance that any sequence can reach, and the comparability sequence with the highest GRG will be the most similar to it. Among all the alternatives, the corresponding comparability sequence alternative will perform better.

\section{Identification of the Selection Requirements}

The model for the MCDM was created based on the materials requirements for cycling helmets in this study (Mithun et al. 2013; Bharath and Basavarajappa 2016; Campilho 2017; Bharath et al. 2018). According to Bahrami et al. (2020), material constraints and mechanical properties are two options for selecting materials for cyclist helmets, where these attributes help in terms of safety and comfort, as well as longer use duration, particularly during the high temperature summers due to lack of ventilation. Such conditions increase human stress levels. Helmets are necessary to protect the rider's head in the event of an accident. According to Firoz et al. (2010), the helmet must be designed in such a way that it improves safety without slowing down the rider's speed while being comfortable for the user.

Mechanical qualities and material restrictions, as previously stated, are the most critical considerations for cycling helmet materials. Grey relational analysis is a part of grey system theory used to solve problems with extensive interrelationships between various criteria and variables (Geum et al. 2011; Jayakrishna and Vinodh 2017). Grey relational analysis is used to assess the link between selection criteria and objectives when a substantial sample size is not available, and the sample's distribution cannot be determined. Grey relational analysis takes nonlinear constraint circumstances into account (contradictory criteria). Grey relational analysis is a rating system for various materials (alternatives) based on a set of criteria. For translating qualitative to quantitative data, MCDM approaches require experts' subjective opinions on a scale or the use of language factors. This could lead to expert prejudice for specific characteristics. Grey relational analysis achieves its goal by relying on reliable data. Grey relational analysis was chosen as the solution methodology in this investigation for these reasons. The study demonstrates how GRA may identify the essential elements that influence the selection of alternative materials in terms of mechanical qualities and material restrictions. For an ordered pair of mechanical qualities and possible material limitations, the GRG was calculated. Using the 
MCDM technique in conjunction with mechanical parameters and material limitations had significantly improved the material selection process. The optimum material was chosen based on grey relational coefficients after numerous computations with GRA. The study's findings assisted decision-makers in making the best decision possible.

As a result, 10 natural fibre properties were determined. These criteria were clustered according to the general requirements of the materials for cycling helmet application and the design and production aspects. The critical criteria for meeting the materials requirement were identified to be "performance", "moisture resistance", and "cost" (price), with associated material attributes and limitation properties of the natural fibre being considered. In the performance of cyclist helmets, weight is a vital comfort aspect. The helmet's design corresponds to the physiological aspects of the human body. Only a safety helmet that matches the physiological properties of the human body can provide a more comfortable experience for the wearer. On the other hand, the helmet's unsuitable structural design may cause pain to the wearer, according to Hao et al. (2019). Furthermore, Ehrlenspiel et al. (2007) found that lightweight design approaches resulted in low-cost devices. According to Wu et al. (2018), the low water resistance of natural fibre-reinforced composites (NFRC) was a limitation in their widespread application. This was owing to the fibre's inherent moisture absorption behavior. Because cycling activity is sometimes done in a humid environment, moisture resistance is an important feature to consider. The cost was chosen as one of the primary criteria by Garofalo et al. (2019), because practically, all departments influence a company's costs, with product development and production being the most important. As a result, the "cost" of natural fibre was chosen as one of the primary criteria, as it can influence the entire manufacturing cost. Table 2 shows the structure of the primary selection criteria and the ten natural fibre properties that will be evaluated for choosing the best natural fibre in biocomposites for cycling helmet applications.

\section{Development of Candidate Materials}

Ten natural fibres were evaluated based on data collected from recent literature for material selection. Ten natural fibres were selected because of their comparable and complete data obtained from the literature. In addition, 8 out of the 10 listed materials were from local sources. There are abundant plant fibres that have the potential as alternative materials for consumer goods. Hence, natural fibres can also help to reduce crop waste and increase the community economy towards sustainability. These natural fibre candidates are shown in Fig. 2 and grouped according to their classifications. The selected natural fibres' physical and mechanical properties could be obtained by carrying out experimental work for data validation. However, this was beyond the scope of the study and resources as well as the limited time. Thus, data were collected from recent and prominent literature. Comparable and complete data of (10) ten natural fibre alternatives were gathered from recent literature published from 2017 to 2021. The selected natural fibre data are arranged in Table 3. In this case, using the average values helped reduce data dispersion. The ten selected attributes of natural fibre were selected to understand their priorities. Experts' evaluations were gathered using an electronic survey questionnaire sent personally to the identified experts in natural fibre composites. The identified experts were required to have a degree in a related area of study with at least three years of experience in a biocomposite related industry. 


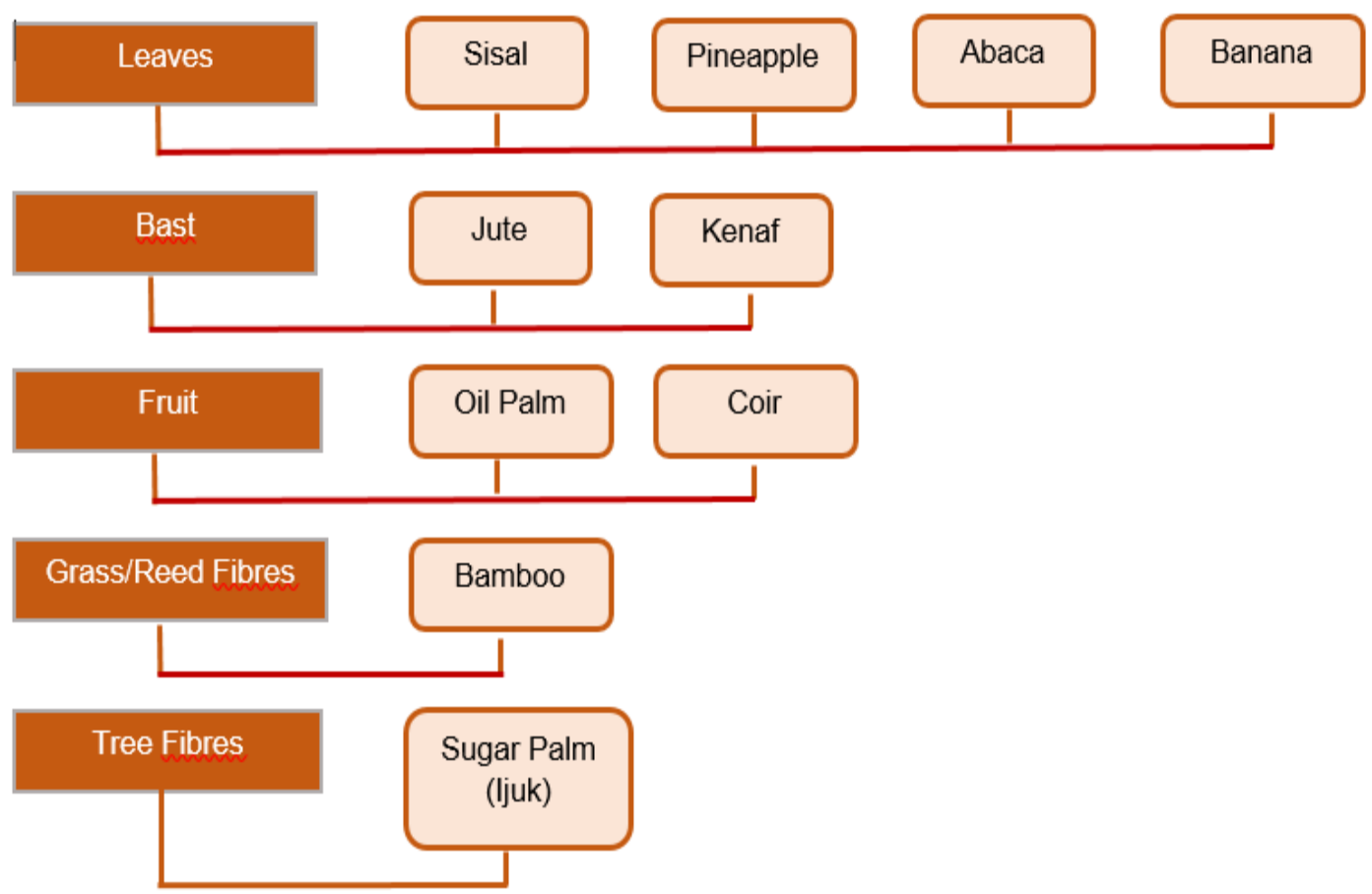

Fig. 2. Ten candidates of natural fibres according to their classification

\begin{tabular}{ll}
\hline ANSWER CHOICE & VALUE \\
\hline Extremely low priority & 1 \\
Very low priority & 2 \\
Low priority & 3 \\
Somewhat low priority & 4 \\
Neutral & 5 \\
Somewhat high priority & 6 \\
High priority & 7 \\
Very high priority & 8 \\
Extremely high priority & 9 \\
\hline
\end{tabular}

Fig. 3. Coding value to interpret

From 13 experts who participated in the survey, 12 of them were $\mathrm{PhD}$ holders and had published at least one peer-reviewed paper, and 10 of them had more than five years of experience in research related to the study of biocomposites. They rated the importance of each criterion using the scale, as shown in Fig. 3 below. These survey data were used to select which equation to employ next: Eq. 1 if the intended value of the performance attribute was larger (LIB) or Eq. 2 if the desired value of the attribute was smaller (SIB). 
Table 1. Tabulated Values of the Survey Scores and GRA Generating

\begin{tabular}{|c|c|c|c|c|c|c|c|c|c|c|}
\hline \multirow[t]{2}{*}{ EXPERT } & Density & $\begin{array}{l}\text { Tensile } \\
\text { Strength }\end{array}$ & $\begin{array}{l}\text { Young's } \\
\text { Modulus }\end{array}$ & $\begin{array}{c}\text { Elongation } \\
\text { to Break }\end{array}$ & $\begin{array}{l}\text { Fiber } \\
\text { Length }\end{array}$ & Lignin & Cellulose & $\begin{array}{l}\text { Moisture } \\
\text { Content }\end{array}$ & Hemicellulose & $\begin{array}{c}\text { Production } \\
\text { Rate }\end{array}$ \\
\hline & SS & SS & SS & SS & SS & SS & SS & SS & SS & SS \\
\hline E1 & 9 & 9 & 7 & 9 & 3 & 8 & 8 & 8 & 6 & 7 \\
\hline E2 & 9 & 9 & 9 & 9 & 9 & 1 & 9 & 9 & 5 & 9 \\
\hline E3 & 9 & 9 & 9 & 8 & 9 & 9 & 5 & 7 & 7 & 7 \\
\hline E4 & 5 & 9 & 6 & 6 & 5 & 8 & 7 & 8 & 8 & 9 \\
\hline E5 & 9 & 9 & 9 & 9 & 7 & 6 & 6 & 9 & 6 & 8 \\
\hline E6 & 7 & 9 & 9 & 8 & 6 & 6 & 8 & 8 & 6 & 7 \\
\hline E7 & 8 & 9 & 9 & 9 & 8 & 6 & 6 & 8 & 8 & 9 \\
\hline E8 & 5 & 9 & 9 & 9 & 4 & 3 & 9 & 8 & 3 & 1 \\
\hline E9 & 7 & 9 & 9 & 9 & 7 & 3 & 5 & 7 & 2 & 5 \\
\hline E10 & 9 & 9 & 9 & 9 & 9 & 9 & 9 & 9 & 9 & 6 \\
\hline E11 & 9 & 9 & 9 & 9 & 9 & 5 & 9 & 9 & 5 & 9 \\
\hline E12 & 7 & 8 & 8 & 7 & 9 & 7 & 7 & 7 & 6 & 7 \\
\hline E13 & 3 & 8 & 7 & 5 & 8 & 5 & 6 & 7 & 5 & 7 \\
\hline $\begin{array}{c}\text { GRA } \\
\text { Generating }\end{array}$ & SIB & LIB & LIB & LIB & LIB & LIB & LIB & LIB & SIB & LIB \\
\hline
\end{tabular}


Table 2. Selection Criteria and Alternatives Developed to Find the Most Suitable Natural Fibre in Biocomposites for Cyclist Helmet Application (Al-Oqla and Salit 2017; Mastura et al. 2017; Salwa et al. 2019)

\begin{tabular}{|l|l|l|}
\hline \multicolumn{1}{|c|}{ Criteria } & \multicolumn{1}{|c|}{ Alternatives } & \multicolumn{1}{c|}{ Description } \\
\hline \multirow{4}{*}{ Performance } & Tensile strength & To determine the durability and strength of materials \\
\cline { 2 - 3 } & Young's modulus & To measure elastic constant to resist deformation when stress is applied \\
\cline { 2 - 3 } & Elongation at break & To determine the strength and toughness level Young's \\
\cline { 2 - 3 } & Density & To identify lighter natural fibres \\
\cline { 2 - 3 } & Cellulose & To determine the degree of polymerisation and reflect the mechanical properties \\
\cline { 2 - 3 } & Lignin & To predict the rigidity of the fibres \\
\cline { 2 - 3 } & Fibre's length & To predict impact strength of the fibres and bonding condition at the interface \\
\hline \multirow{2}{*}{$\begin{array}{l}\text { Moisture } \\
\text { Resistance }\end{array}$} & Hemicellulose & To predict biodegradation and lower moisture absorption \\
\cline { 2 - 3 } & Moisture content & To determine lower moisture for prediction of relative performance under wet conditions \\
\hline Cost & Production rate & To evaluate the ability of the natural fibre to be processed \\
\hline
\end{tabular}


Table 3. Qualitative Measures of Natural Fibres Alternatives in Biocomposites Proposed for Cyclist Helmet Application (Djafari Petroudy 2017; Mastura et al. 2017; Raja et al. 2017; Lau et al. 2018; Salwa et al. 2019; Gholampour and Ozbakkaloglu 2020; Li et al. 2020; Sahu and Gupta 2020; Zwawi 2021)

\begin{tabular}{|c|c|c|c|c|c|c|c|c|c|c|c|}
\hline \multirow[b]{2}{*}{ No. } & \multirow[b]{2}{*}{ Fibre } & \multicolumn{7}{|c|}{ Performance } & \multicolumn{2}{|c|}{ Moisture Resistance } & \multirow{2}{*}{$\begin{array}{c}\text { Cost } \\
\begin{array}{c}\text { Production Rate } \\
\left(10^{3} \text { tons }\right)\end{array}\end{array}$} \\
\hline & & $\begin{array}{l}\text { Density } \\
\left(\mathrm{g} / \mathrm{cm}^{3}\right)\end{array}$ & $\begin{array}{c}\text { Tensile } \\
\text { Strength } \\
\text { (MPa) }\end{array}$ & $\begin{array}{l}\text { Young's } \\
\text { Modulus } \\
\text { (Gpa) }\end{array}$ & $\begin{array}{l}\text { Elongation } \\
\text { to Break (\%) }\end{array}$ & $\begin{array}{c}\text { Fiber } \\
\text { Length } \\
(\mathrm{mm})\end{array}$ & Lignin (\%) & $\begin{array}{c}\text { Cellulose } \\
\text { (\%) }\end{array}$ & $\begin{array}{c}\text { Moisture } \\
\text { Content (\%) }\end{array}$ & $\begin{array}{l}\text { Hemicellulose } \\
(\%)\end{array}$ & \\
\hline 1 & Banana & 1.35 & 529 to 914 & 8 to 32 & 3 & 10 & 5 to 10 & 62 to 64 & 10 to 12 & 12.5 & 117 \\
\hline 2 & Oil Palm & 0.7 to 1.55 & 80 to 248 & 0.6 to 25 & 3.2 & 115 & 13.2 to 29 & 42.7 to 65 & 65 & 14.94 to 33.5 & 40 \\
\hline 3 & Pineapple & 0.8 to 1.6 & 170 to 1627 & 1.44 to 82 & 2.4 & 30 & 8.3 to 12.7 & 80.5 & 10 to 13 & 17.5 & 74 \\
\hline 4 & Sisal & 1.5 & 511 to 635 & 8.5 to 40 & 3 to 7 & 900 & 8 to 11 & 60 to 77 & 11 & 11.5 to 14 & 378 \\
\hline 5 & ljuk (Sugar Palm) & $\begin{array}{l}1.22 \text { to } \\
1.45\end{array}$ & $\begin{array}{l}122 \text { to } \\
304.2\end{array}$ & 2.11 to 5.9 & 8.9 to 29.9 & 1190 & $\begin{array}{l}31.5 \text { to } \\
41.97\end{array}$ & $\begin{array}{l}43.75 \text { to } \\
52.3\end{array}$ & 5.5 to 8.67 & 9.94 to 13.3 & 40 \\
\hline 6 & Abaca & 1.5 & 400 to 980 & 31.1 to 33.6 & 3 to 10 & 3000 & 7 to 12 & 56 to 63 & 15 & 21 to 25 & 70 \\
\hline 7 & Jute & 1.3 to 1.5 & 200 to 773 & 9 to 31 & 1.5 to 1.8 & 60.75 & 9 to 13 & 59 to 71.5 & 12.5 to 13.7 & 12 to 20 & 2300 \\
\hline 8 & Coir & 1.2 to 1.5 & 175 to 180 & 3 to 7 & 30 & 85 & 45 & 45.6 & 8 to 11.36 & 20 & 100 \\
\hline 9 & Kenaf & 1.4 & 930 & 11 to 60 & 1.5 & 500 & 17 to 21.5 & 53.5 & 6.2 to 12 & 21 to 33 & 970 \\
\hline 10 & Bamboo & 0.6 to 1.11 & 140 to 800 & 30 to 50 & 1.4 & 90 & 21 to 31 & 26 to 43 & 8.9 & 20.5 & 30000 \\
\hline & $\begin{array}{c}\text { GRA } \\
\text { GENERATING }\end{array}$ & SIB & LIB & LIB & LIB & LIB & LIB & LIB & LIB & SIB & LIB \\
\hline
\end{tabular}


This step is critical for normalising the choice matrix and forming the attribute comparability sequence (Geum et al. 2011; Jayakrishna and Vinodh 2017). The comparability sequence was derived from the recent literature review and supported by survey scores obtained to ensure that both results from the recent literature and expert survey were in line with one another. The tabulated values of the survey scores and GRA generating are available in Table 1.

\section{RESULTS AND DISCUSSION}

In this study, the GRA technique was chosen because grey systems lack complete information, making it difficult to discern a trend or relationship between the input factors and the desired objectives. Instead of dealing with massive amounts of data using a statistical model, GRA is a real-time modelling approach using only minimal data. Grey relational analysis is used to find GRG by defining the relationships between the factors and identifying the essential factors that have a substantial impact on the desired outcomes. The material selection problem is identical to the grey system in that it includes competing criteria with uncertain combined effects on the outcome. Based on the data of Table 3, the GRA procedure is as follows:

\section{Grey relational sequence generation}

The primary goal of grey relational generation is to convert raw data into identical sequences. With tensile strength, Young's modulus, elongation to break, fibre's length, lignin, cellulose, and moisture contents, as well as production rate using Eq. 1, the desired values of the performance attributes were larger (LIB). Meanwhile, the grey relational generation process adopted Eq. 2 for the desired value of the attribute were smaller (SIB) for density and hemicellulose attributes. For example, in the case of the density attribute, 1.5 was the maximum value from alternatives No. 4 and No. 6, and the minimum value was 0.86 from alternative No. 10. Using Eq. 2, the results of grey relational generated from alternative No. 1 was equal to $(1.5-1.35) /(1.5-0.86)=0.2326$. All findings of grey relational generating are shown in Table 4.

\section{Derivation of reference sequence}

In Table $4, X_{0}$ is the reference sequence. After the grey relational sequence was generated, the comparability sequence values, $X_{i}$ were scaled into the range $[0,1]$. The alternative having the greater $X_{i}$ value (equal to unity) performed better. However, this type of performance criterion was uncommon. As a result, a reference sequence $X_{0}$ was defined, with values equal to 1 , and it was compared to the generated sequence. The better alternative was chosen from the one exhibiting the highest degree of similarity between the two sequences. The reference sequence was expressed as follows:

$$
X_{0}=\left(x_{01}, x_{02}, \ldots, x_{0 j}, \ldots, x_{0 n}\right)=(1,1, \ldots, 1 \ldots, 1) .
$$

\section{Calculation of grey relational coefficient}

After calculating $\Delta_{i j}, \Delta_{\max }$, and $\Delta_{\min }$, all grey relational coefficients can be determined from Eq. 3. For example, $\Delta_{i 1}=|1-0.2326|=0.7674, \Delta_{\max }=1$, and $\Delta_{\min }$ $=0$, if $\delta=0.5$, then $\gamma\left(x_{0 j}, x_{i j}\right)=(0+0.5 \times 1) /(0.7674+0.5 \times 1)=0.3945$. The entire results for the grey relational coefficient are shown in Table 5. 
Table 4. Step 1 and 2- Results of Grey Relational Generating for Cyclist Helmet Application

\begin{tabular}{|c|c|c|c|c|c|c|c|c|c|c|}
\hline \multicolumn{10}{|c|}{ Steps 1 and 2 } \\
\hline $\begin{array}{c}\text { Alternative } \\
\text { No. }\end{array}$ & $\begin{array}{c}\text { Density } \\
\left(\mathbf{g} / \mathbf{c m}^{\mathbf{3}}\right)\end{array}$ & $\begin{array}{c}\text { Tensile } \\
\text { Strength } \\
(\mathbf{M P a})\end{array}$ & $\begin{array}{c}\text { Young's } \\
\text { Modulus } \\
(\mathbf{G p a})\end{array}$ & $\begin{array}{c}\text { Elongation } \\
\text { to Break } \\
(\%)\end{array}$ & $\begin{array}{c}\text { Fiber Length } \\
(\mathbf{m m})\end{array}$ & $\begin{array}{c}\text { Lignin } \\
(\%)\end{array}$ & $\begin{array}{c}\text { Cellulose } \\
(\%)\end{array}$ & $\begin{array}{c}\text { Moisture } \\
\text { Content } \\
(\%)\end{array}$ & $\begin{array}{c}\text { Hemicellulose } \\
(\%)\end{array}$ & $\begin{array}{c}\text { Production } \\
\text { Rate } \\
(\mathbf{1 0} \text { tonne) }\end{array}$ \\
\hline $\mathbf{1}$ & 0.2326 & 0.7278 & 0.4241 & 0.0559 & 0.0000 & 0.0000 & 0.5978 & 0.0676 & 0.9428 & 0.0026 \\
\hline $\mathbf{2}$ & 0.5814 & 0.0000 & 0.2332 & 0.0629 & 0.0351 & 0.3627 & 0.4207 & 1.0000 & 0.1808 & 0.0000 \\
\hline $\mathbf{3}$ & 0.4651 & 0.9589 & 1.0000 & 0.0350 & 0.0067 & 0.0800 & 1.0000 & 0.0762 & 0.6177 & 0.0011 \\
\hline $\mathbf{4}$ & 0.0000 & 0.5339 & 0.5368 & 0.1259 & 0.2977 & 0.0533 & 0.7391 & 0.0676 & 0.9265 & 0.0113 \\
\hline $\mathbf{5}$ & 0.2558 & 0.0641 & 0.0000 & 0.6294 & 0.3946 & 0.7796 & 0.2940 & 0.0000 & 1.0000 & 0.0000 \\
\hline $\mathbf{6}$ & 0.0000 & 0.6867 & 0.7516 & 0.1783 & 1.0000 & 0.0533 & 0.5435 & 0.1367 & 0.2601 & 0.0010 \\
\hline $\mathbf{7}$ & 0.1550 & 0.4210 & 0.4241 & 0.0087 & 0.0170 & 0.0933 & 0.6685 & 0.1039 & 0.7152 & 0.0754 \\
\hline $\mathbf{8}$ & 0.2326 & 0.0176 & 0.0264 & 1.0000 & 0.0251 & 1.0000 & 0.2413 & 0.0448 & 0.4551 & 0.0020 \\
\hline $\mathbf{9}$ & 0.1550 & 1.0000 & 0.8351 & 0.0035 & 0.1639 & 0.3133 & 0.4152 & 0.0348 & 0.0000 & 0.0310 \\
\hline $\mathbf{1 0}$ & 1.0000 & 0.3995 & 0.9544 & 0.0000 & 0.0268 & 0.4933 & 0.0000 & 0.0313 & 0.4226 & 1.0000 \\
\hline
\end{tabular}


Table 5. Step 3- Results of Grey Relational Coefficient for Cyclist Helmet Application

\begin{tabular}{|c|c|c|c|c|c|c|c|c|c|c|}
\hline \multicolumn{11}{|c|}{ Step 3} \\
\hline \multirow[b]{2}{*}{$\begin{array}{c}\text { Alternative } \\
\text { No. }\end{array}$} & \multicolumn{7}{|c|}{ Performance } & \multicolumn{2}{|c|}{ Moisture Resistance } & \multirow{2}{*}{$\begin{array}{c}\text { Cost } \\
\begin{array}{c}\text { Production } \\
\text { Rate } \\
\left(10^{3} \text { tonne }\right)\end{array}\end{array}$} \\
\hline & $\begin{array}{l}\text { Density } \\
\left(\mathrm{g} / \mathrm{cm}^{3}\right)\end{array}$ & $\begin{array}{c}\text { Tensile } \\
\text { Strength } \\
\text { (MPa) }\end{array}$ & $\begin{array}{c}\text { Young's } \\
\text { Modulus } \\
\text { (Gpa) }\end{array}$ & $\begin{array}{c}\text { Elongation } \\
\text { to Break } \\
(\%)\end{array}$ & $\begin{array}{l}\text { Fiber } \\
\text { Length } \\
(\mathrm{mm})\end{array}$ & $\begin{array}{l}\text { Lignin } \\
(\%)\end{array}$ & $\begin{array}{c}\text { Cellulose } \\
(\%)\end{array}$ & $\begin{array}{c}\text { Moisture } \\
\text { Content } \\
(\%)\end{array}$ & $\begin{array}{c}\text { Hemicellulose } \\
\text { (\%) }\end{array}$ & \\
\hline 1 & 0.3945 & 0.6475 & 0.4647 & 0.3462 & 0.3333 & 0.3333 & 0.5542 & 0.3491 & 0.8973 & 0.3339 \\
\hline 2 & 0.5443 & 0.3333 & 0.3947 & 0.3479 & 0.3413 & 0.4396 & 0.4632 & 1.0000 & 0.3790 & 0.3333 \\
\hline 3 & 0.4831 & 0.9240 & 1.0000 & 0.3413 & 0.3348 & 0.3521 & 1.0000 & 0.3512 & 0.5667 & 0.3336 \\
\hline 4 & 0.3333 & 0.5176 & 0.5191 & 0.3639 & 0.4159 & 0.3456 & 0.6571 & 0.3491 & 0.8719 & 0.3359 \\
\hline 5 & 0.4019 & 0.3482 & 0.3333 & 0.5743 & 0.4523 & 0.6941 & 0.4146 & 0.3333 & 1.0000 & 0.3333 \\
\hline 6 & 0.3333 & 0.6148 & 0.6681 & 0.3783 & 1.0000 & 0.3456 & 0.5227 & 0.3667 & 0.4033 & 0.3336 \\
\hline 7 & 0.3718 & 0.4634 & 0.4647 & 0.3353 & 0.3371 & 0.3555 & 0.6013 & 0.3581 & 0.6371 & 0.3510 \\
\hline 8 & 0.3945 & 0.3373 & 0.3393 & 1.0000 & 0.3390 & 1.0000 & 0.3972 & 0.3436 & 0.4785 & 0.3338 \\
\hline 9 & 0.3718 & 1.0000 & 0.7520 & 0.3341 & 0.3742 & 0.4213 & 0.4609 & 0.3412 & 0.3333 & 0.3404 \\
\hline 10 & 1.0000 & 0.4543 & 0.9164 & 0.3333 & 0.3394 & 0.4967 & 0.3333 & 0.3404 & 0.4641 & 1.0000 \\
\hline
\end{tabular}


Table 6. Step 4 - Results of Grey Relational Grade and Rank for Cyclist Helmet Application

\begin{tabular}{|c|c|c|}
\hline Fibre & $\begin{array}{c}\text { Grey Relational } \\
\text { Grade }\end{array}$ & $\begin{array}{c}\text { Ranking Result of } \\
\text { GRA }\end{array}$ \\
\hline Pineapple & 0.5687 & 1 \\
\hline Bamboo & 0.5678 & 2 \\
\hline Abaca & 0.4966 & 3 \\
\hline Coir & 0.4963 & 4 \\
\hline ljuk (Sugar Palm) & 0.4885 & 5 \\
\hline Kenaf & 0.4729 & 6 \\
\hline Sisal & 0.4709 & 7 \\
\hline Banana & 0.4654 & 8 \\
\hline Oil Palm & 0.4577 & 9 \\
\hline Jute & 0.4275 & 10 \\
\hline
\end{tabular}




\section{Calculation of $G R G$}

All performance attributes were assumed to be of equal importance in this situation. As a result, the ten performance attributes were all given the same weight (1/10). The GRG was determined using Eq. 4, and is presented in column 2 of Table 6. The GRA's ranking results are displayed in column 3 of Table 6 . Synthesised results concerning the main criteria then produced a list with ten alternatives of natural fibres ranked according to their GRA grade scores calculated by the Microsoft Excel 2016 software (Microsoft, Redmond, WA, USA) with corresponding formula. The results are shown in Fig. 4. Pineapple had the highest grade of 0.5687 , which was at the top of the rank. The second-highest grade was bamboo with a grade of 0.5678 , followed by abaca, coir, ijuk (sugar palm), kenaf, sisal, and banana with the grades of $0.4966,0.4963,0.4885,0.4729,0.4709$, and 0.4654 , respectively. Oil palm and jute were at the bottom of the rank with grades of 0.4577 and 0.4275 .

It is essential to acknowledge that each natural fibre has different properties corresponding to its chemical composition and morphology (Johansson et al. 2012; Muhammad Huzaifah et al. 2017). As a result, in addition to the overall findings, the scores for each main criterion were recorded and converted into a performance graph for each alternative criterion (Fig. 4). Bamboo grade score was the highest for the "Cost" criteria, whereas oil palm and ijuk (sugar palm) were the complete opposite. Oil palm obtained a high score in the "Moisture Resistance", whereas kenaf was completely contrary. Remarkably, the pineapple score was the highest for the "Performance", followed by bamboo, with a minimal difference grade value obtained. The 'overall' line in the graph shows the final output result after combining these three criteria (performance, moisture resistance, and cost). The overall results show that the trend almost looks alike to performance criteria. It can be highlighted that performance criteria are an essential attribute in this study.
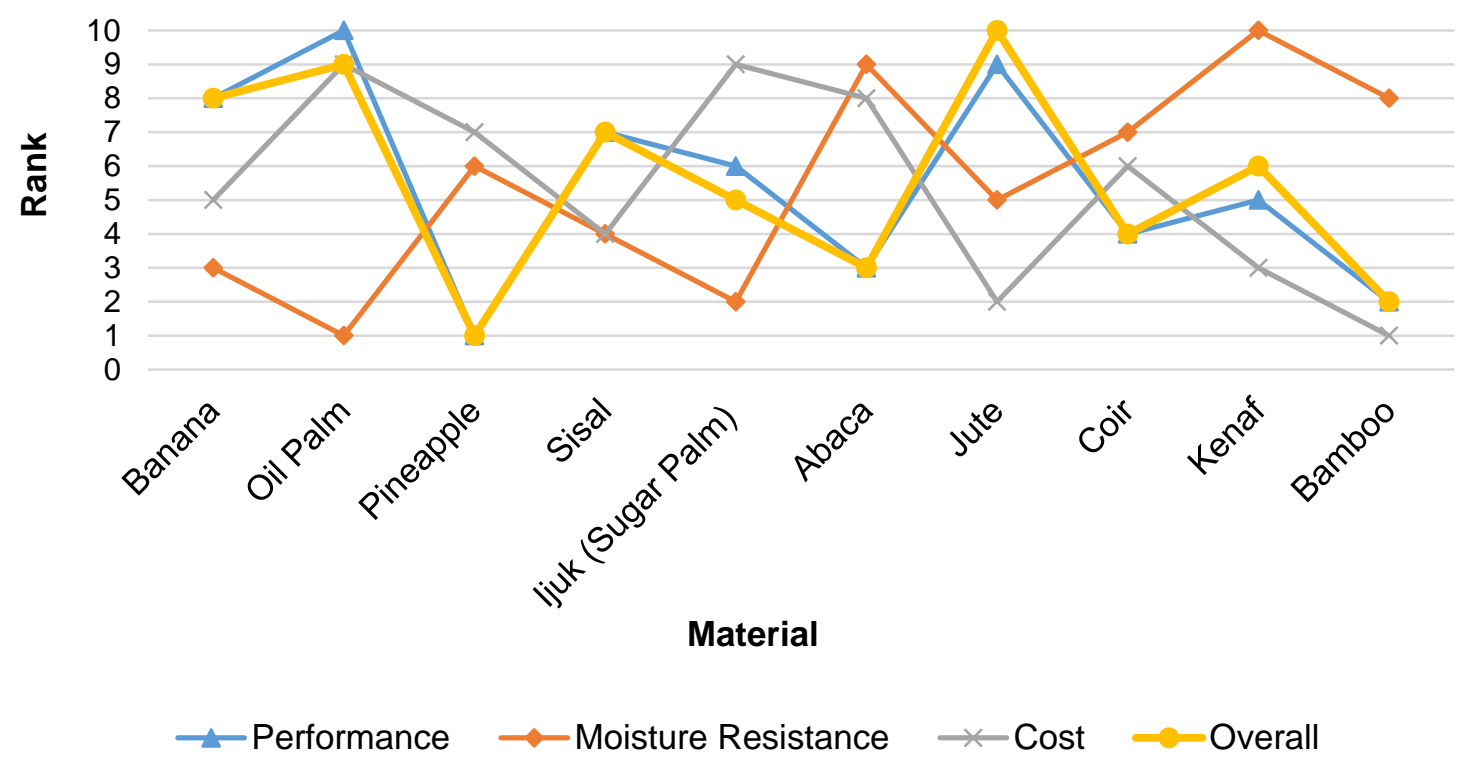

Fig. 4. The GRA final synthesis results with respect to all criteria

The five highest values of "Performance," namely "Density", "Tensile Strength", "Young's Modulus", "Elongation at Break", "Fiber's Length", "Lignin", and "Cellulose", 
were then synthesised, and the "Performance" results of the alternatives are presented in Fig. S1. "Young's Modulus" and "Cellulose" were the two sub-criteria for which pineapple received the highest ratings. Bamboo received a good grade for "Density," but it received the lowest score for "Cellulose." Coir had the maximum rank for "Elongation at Break" and "Lignin" among the five values. On the other hand, Abaca scored well for "Fiber's Length" but poorly for "Density." In the second place, ijuk (sugar palm) scores for "Elongation at Break", "Fiber's Length", and "Lignin" were pretty high. Ijuk's (sugar palm) "Young's Modulus" score was relatively low. Each alternate value of "Moisture Resistance," i.e., "Moisture Content" and "Hemicellulose," was also observed, with the findings shown in Fig. S2. Oil palm had the highest "Moisture Content" score, while ijuk (sugar palm) had the lowest. Ijuk (sugar palm) got a high "Hemicellulose" score but a lower "Moisture Content" score. Interestingly, the scores for pineapple, jute, and coir were nearly the same in both sub-criteria and were almost identical. A similar analysis was carried out for the "Cost" sub-criteria. The only criterion would be the "Production Rate." The outcomes were recorded and interpreted into a graph to help comprehend the options and sub-criteria (Fig. S3). Bamboo, jute, kenaf, sisal, banana, coir, pineapple, and abaca all received high marks for "Production Rate." Ijuk (sugar palm) and oil palm were at the bottom of the list.

A generalisation could be made that classes of fibres do not give any effect to their ranks. Pineapple is a leaf fibre at the top rank followed by bamboo a grass/reed fibre. From the analysis of fibres' with respect to the main criteria (Fig. 5), for the "Cost" category, bamboo had the highest score, while oil palm and ijuk (sugar palm) had the lowest. Oil palm received a good grade in the "Moisture Resistance" category, whereas kenaf did not. Surprisingly, the pineapple had the most excellent "Performance" score, followed by bamboo, which had the smallest difference grade value.

\section{Error Analysis}

The Distinguishing Coefficient $(\delta)$ is an essential parameter of GRA, a leading multi-criteria decision making (MCDM) model of grey system theory, a multifaceted and intelligent field developed by Chinese scientists in the 1980s. However, in general, the researchers assume $\delta=0.5$, where the current study examined this practice. Some researchers have debated that the $\delta$ values variation does not affect the factors ranking through GRA. In contrast, the study demonstrated that the variation in $\delta$ can affect the order (Mahmoudi et al. 2020). The distinguishing coefficient's aim is to compress or widen the grey relational coefficient's range, for instance, the case where three alternatives exist, $a$, $b$, and $c$. If $\Delta_{\mathrm{aj}}=0.1, \Delta_{\mathrm{bj}}=0.4$, and $\Delta_{\mathrm{cj}}=0.9$, for attribute $j$, alternative $a$ is the closest to the reference sequence. After grey relational generation using Eqs. 1 through $4, \Delta_{\max }$ will be equal to 1 and $\Delta_{\min }$ will be equal to 0 . Figure 5 shows the grey relational coefficient data when different distinguishing coefficients were adopted. Initially in this study, the distinguishing coefficient was fixed at 0.5 . Furthermore, as an error analysis, this study examined the impact on GRA findings when the distinguishing coefficients were set at 0.1 , $0.3,0.5,0.7$, and 0.9 , respectively. The results are presented in Table 7. 


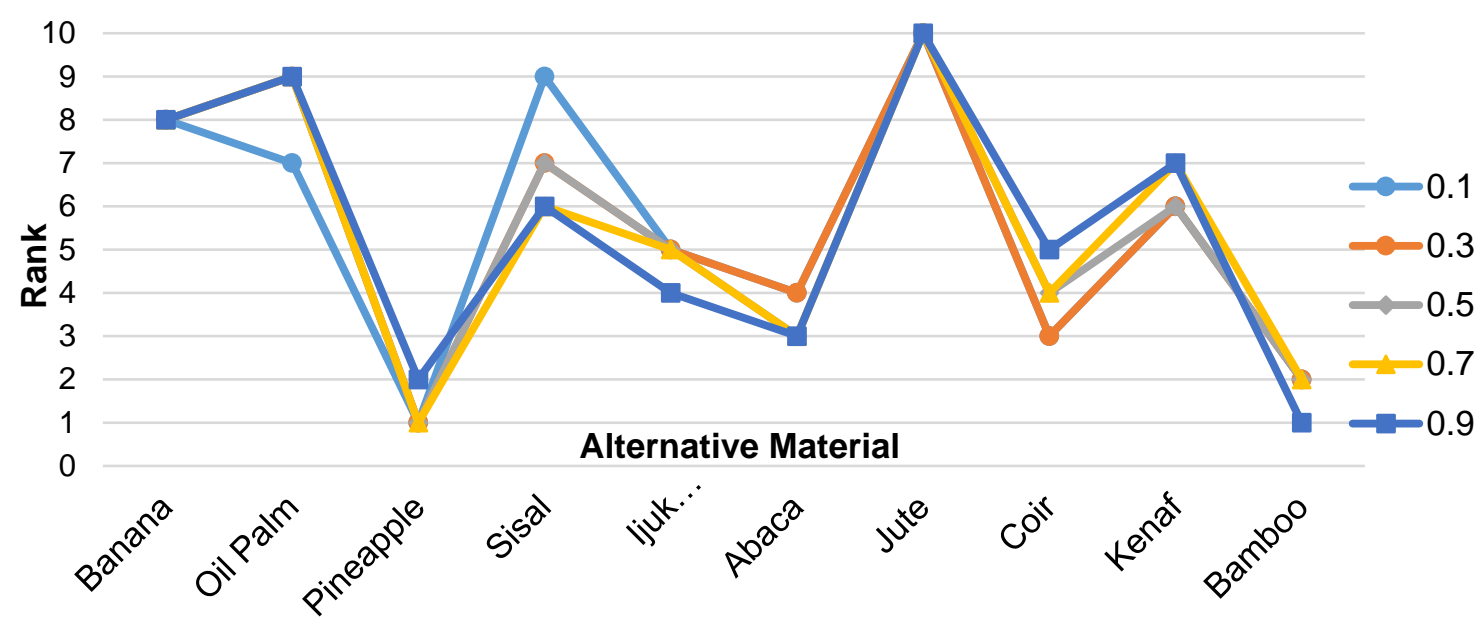

Fig. 5. The impact of distinguishing coefficient on the results of GRA to find the best natural fibre as reinforcement in biocomposite for cyclist helmet design

Pineapple was chosen as the best natural fibre for use as reinforcement in biocomposites for cycling helmets. Furthermore, bamboo and abaca frequently appeared in the top three rankings. Banana, oil palm, and jute, on the other hand, were consistently in the bottom three in all situations. For the specific design purpose, it was determined that jute was the least preferable natural fibre for reinforcing biocomposites.

Despite the highly validated results, the authors believe that the natural fibre selection method might have been more comprehensive if additional details from other criteria had been included. The formulation of the required criteria must take into account a variety of factors when making a decision. As a result, in the natural fibre selection process, decision-makers must design the selection criteria as precise as possible referring to the specific demand, as this will affect the selection results.

Table 7. Summary of Error Analysis Based on Five Circumstances

\begin{tabular}{|c|c|c|c|c|c|c|}
\hline Rank & $\begin{array}{c}\text { Original } \\
\text { Results }\end{array}$ & $\mathbf{0 . 1}$ & $\mathbf{0 . 3}$ & $\mathbf{0 . 5}$ & $\mathbf{0 . 7}$ & $\mathbf{0 . 9}$ \\
\hline$\# 1$ & Pineapple & Pineapple & Pineapple & Pineapple & Pineapple & Bamboo \\
\hline$\# 2$ & Bamboo & Bamboo & Bamboo & Bamboo & Bamboo & Pineapple \\
\hline$\# 3$ & Abaca & Coir & Coir & Abaca & Abaca & Abaca \\
\hline$\# 4$ & Coir & Abaca & Abaca & Coir & Coir & $\begin{array}{c}\text { ljuk (Sugar } \\
\text { Palm) }\end{array}$ \\
\hline$\# 5$ & $\begin{array}{c}\text { ljuk (Sugar } \\
\text { Palm) }\end{array}$ & $\begin{array}{c}\text { ljuk (Sugar } \\
\text { Palm) }\end{array}$ & $\begin{array}{c}\text { ljuk (Sugar } \\
\text { Palm) }\end{array}$ & $\begin{array}{c}\text { ljuk (Sugar } \\
\text { Palm) }\end{array}$ & $\begin{array}{c}\text { ljuk (Sugar } \\
\text { Palm) }\end{array}$ & Coir \\
\hline$\# 6$ & Kenaf & Kenaf & Kenaf & Kenaf & Sisal & Sisal \\
\hline$\# 7$ & Sisal & Oil Palm & Sisal & Sisal & Kenaf & Kenaf \\
\hline$\# 8$ & Banana & Banana & Banana & Banana & Banana & Banana \\
\hline$\# 9$ & Oil Palm & Sisal & Oil Palm & Oil Palm & Oil Palm & Oil Palm \\
\hline$\# 10$ & Jute & Jute & Jute & Jute & Jute & Jute \\
\hline
\end{tabular}


Time of fibre harvest, the extraction process, aspect ratio, and the fibre's pretreatment and storage procedures are all additional data that should be measured (Pickering et al. 2016). Many parameters influence the mechanical properties of reinforcement in polymer composites, including fibre-matrix adhesion, the volume fraction of the fibres, fibre aspect ratio $(l / d)$, and fibre orientation ( $\mathrm{Su}$ et al. 2018). Aside from that, the surface treatment type used and nanotechnology to achieve optimal interfacial bonding with biopolymer matrices could influence the final selection outcomes (Saba et al. 2017). Natural fibres' characteristics data and related information are not yet available in any established materials commercial database, which was one of the key hurdles in this selection procedure. As Sapuan et al. (2011) pointed out in their paper, gathering a dataset for natural fibre alternatives is critical because "trustworthy and accountable sources on data about natural fibres qualities play a vital part in the selection process."

\section{CONCLUSIONS}

1. This research focused on bicycle helmets design and provides a systematic approach to efficiently guide designers or material engineers in making selections on the optimum natural fibre to develop new revolutionary biocomposite materials for the safety gear application. There were three primary selection criteria and ten subcriteria used to decide on the best natural fibre out of ten options. The GRA method is a practical way to gather expert opinions to address a decision problem in the material selection process. The GRA method was utilised and revealed that pineapple was the best natural fibre with a grade of 0.5687 , followed closely by bamboo with a grade of 0.5678 , and abaca with a grade of 0.4966 .

2. The error analysis was performed to increase the confidence level of the results obtained. Five different circumstances in the error analysis were accompanied to validate the outcome further. Pineapple was at the top of the rank in four out of the five circumstances tested, and it remained at the top score ranking.

3. Other details, such as specific properties, fibre processing and time, as well as fibre treatment, could be included to obtain a more comprehensive selection criteria list and thus receive more comprehensive results for future further development.

\section{ACKNOWLEDGEMENTS}

The authors would like to thank Universiti Putra Malaysia (Seri Kembangan, Malaysia) for financial support and the opportunity doing this study and as well as Universiti Teknikal Malaysia Melaka (Durian Tunggal, Malaysia) and the Ministry of Higher Education Malaysia for providing the scholarship award to the principal author to carry out this research project. 


\section{REFERENCES CITED}

Alam, F., Chowdhury, H., Elmir, Z., Sayogo, A., Love, J., and Subic, A. (2010). “An experimental study of thermal comfort and aerodynamic efficiency of recreational and racing bicycle helmets," Procedia Engineering 2(2), 2413-2418. DOI: 10.1016/j.proeng.2010.04.008

Al-Oqla, F. M, and Omari, M. A. (2017). "Sustainable biocomposites: Challenges, potential and barriers for development," in: Green Biocomposites, M. Jawaid, M. S. Salit, and O. Y. Alothman (eds.), Springer, Cham, Switzerland, pp 13-29. DOI: 10.1007/978-3-319-46610-1_2

Al-Oqla, F. M, and Salit, M. S. (2017). "Material selection for composites," in: Materials Selection for Natural Fiber Composites, Woodhead Publishing, Cambridge, England, pp. 73-105. DOI: 10.1016/B978-0-08-100958-1.00004-9

Al-Oqla, F. M., Sapuan, S. M., Ishak, M. R., and Nuraini, A. A. (2015). "Selecting natural fibers for bio-based materials with conflicting criteria," American Journal of Applied Sciences 12(1), 64-71. DOI: 10.3844/ajassp.2015.64.71

Bahrami, M., Abenojar, J., and Martínez, M. Á. (2020). "Recent progress in hybrid biocomposites: Mechanical properties, water absorption, and flame retardancy," Materials 13(22), article no. 5145. DOI: 10.3390/ma13225145

Bharath, B., Kumar, G. C., Shivanna, G., Hussain, S. S., Chandrashekhar, B., Raj, B. A. S., Kumar, S. A., and Girisha, C. (2018). "Fabrication and mechanical characterization of bio-composite helmet," Materials Today: Proceedings 5(1), 27162720. DOI: 10.1016/j.matpr.2018.01.053

Bharath, K. N., and Basavarajappa, S. (2016). "Applications of biocomposite materials based on natural fibers from renewable resources: A review," Science and Engineering of Composite Materials 23(2), 123-133. DOI: 10.1515/secm-2014-0088

Campilho, R. D. S. G. (2017). "Recent innovations in biocomposite products," in: Biocomposites for High-Performance Applications: Current Barriers and Future Needs Towards Industrial Development, Elsevier, Amsterdam, Netherlands, pp. 275306. DOI: 10.1016/B978-0-08-100793-8.00010-7

Chan, J. W. K., and Tong, T. K. L. (2007). "Multi-criteria material selections and end-oflife product strategy: Grey relational analysis approach," Materials and Design 28(5), 1539-1546. DOI: 10.1016/j.matdes.2006.02.016

Cheung, H., Ho, M., Lau, K., Cardona, F., and Hui, D. (2009). "Natural fibre-reinforced composites for bioengineering and environmental engineering applications," Composites Part B: Engineering 40(7), 655-663. DOI: 10.1016/j.compositesb.2009.04.014

Deng, J. L. (1989). "Grey information space,” The Journal of Grey System 1(2), 103-117. DOI: 10.1007/978-3-642-13938-3_39

Deng, J. L. (1989). "Introduction to grey system theory," The Journal of Grey System 1, 1-24. DOI: couldn't find. (http://www.researchinformation.co.uk/grey/IntroGreySysTheory.pdf)

Djafari Petroudy, S. R. (2017). "3- Physical and mechanical properties of natural fibers," in: Advanced High Strength Natural Fibre Composites in Construction, M. Fan, and F. Fu (eds.), Woodhead Publishing, Cambridge, England, pp. 59-83. DOI:

10.1016/B978-0-08-100411-1.00003-0 
Ehrlenspiel, K., Kiewert, A., and Lindemann, U. (2007). Cost-Efficient Design, M. S. Hundal (ed.), Springer, Berlin, Germany.

Garofalo, J., Walczyk, D., and Bucinell, R. (2019). "Low-cost manufacturing and recycling of advanced biocomposites," Journal of Natural Fibers 16(3), 412-426. DOI: 10.1080/15440478.2017.1423261

Geum, Y., Cho, Y., and Park, Y. (2011) "A systematic approach for diagnosing service failure: Service-specific FMEA and grey relational analysis approach," Mathematical and Computer Modelling 54(11), 3126-3142. DOI: 10.1016/j.mcm.2011.07.042

Gholampour, A., and Ozbakkaloglu, T. (2020). "A review of natural fiber composites: Properties, modification and processing techniques, characterization, applications," Journal of Materials Science 55(3), 829-892. DOI: 10.1007/s10853-019-03990-y

Grand View Research (2018). "Automotive polymer composites market size report by resin (epoxy, polyurethane, polyamide, polypropylene, polyethylene), by application, by product, by end use, by manufacturing, and segment forecasts, 2018-2025," (https://www.grandviewresearch.com/industry-analysis/automotive-polymercomposites-market), Accessed 10 November 2018.

Hao, W., Shan, L., Yang, W., Jingjing, W., Chenyan, L., and Yun, Z. (2019). "Analysis of the influence factors of safety helmet comfort," IOP Conference Series: Earth and Environmental Science 218(1), article ID 012076. DOI: 10.1088/17551315/218/1/012076

Jayakrishna, K., and Vinodh, S. (2017). “Application of grey relational analysis for material and end of life strategy selection with multiple criteria," International Journal of Materials Engineering Innovation 8(3-4), 250-272. DOI: 10.1504/IJMATEI.2017.090241

Johansson, C., Bras, J., Mondragon, I., Nechita, P., Plackett, D., Simon, P., GregorSvetec, D., Virtanen, S., Baschetti, M. G., Breen, C., Clegg, F., and Aucejo, S. (2012). "Renewable fibers and bio-based materials for packaging applications - A review of recent developments," BioResources 7(2), 2506-2552. DOI: 10.15376/biores.7.2.2506-2552

Ju-Long, D. (1982). "Control problems of grey systems," Systems and Control Letters 1(5), 288-294. DOI: 10.1016/S0167-6911(82)80025-X

Kulak, O., and Kahraman, C. (2005). "Fuzzy multi attribute selection among transportation companies using axiomatic design and analytic hierarchy process," Information Sciences 170(2-4), 191-210. DOI: 10.1016/j.ins.2004.02.021

Lau, K., Hung, P., Zhu, M., and Hui, D. (2018). "Properties of natural fibre composites for structural engineering applications," Composites Part B: Engineering 136, 222233. DOI: 10.1016/j.compositesb.2017.10.038

Li, M., Pu, Y., Thomas, V. M., Yoo, C. G., Ozcan, S., Deng, Y., Nelson, K., and Ragauskas, A. J. (2020). "Recent advancements of plant-based natural fiberreinforced composites and their applications," Composites Part B: Engineering 200, Article ID 108254. DOI: 10.1016/j.compositesb.2020.108254

Mahmoudi, A., Javed, S., Liu, S., and Deng, X. (2020). "Distinguishing coefficient driven sensitivity analysis of GRA model for intelligent decisions: Application in project management," Technological and Economic Development of Economy 26(3), 621-641. DOI: 10.3846/tede.2019.11890 
Majeed, K., Jawaid, M., Hassan, A., Abu Bakar, A., Abdul Khalil, H. P. S., Salema, A. A., and Inuwa, I. (2013). "Potential materials for food packaging from nanoclay/ natural fibres filled hybrid composites," Materials and Design 46, 391-410.

Mastura, M. T., Sapuan, S. M., Mansor, M. R., and Nuraini, A. A. (2017). "Environmentally conscious hybrid bio-composite material selection for automotive anti-roll bar," The International Journal of Advanced Manufacturing Technology 89(5-8), 2203-2219. DOI: 10.1007/s00170-016-9217-9

Mastura, M. T., Sapuan, S. M., Mansor, M. R., and Nuraini, A. A. (2018). "Materials selection of thermoplastic matrices for 'green' natural fibre composites for automotive anti-roll bar with particular emphasis on the environment," International Journal of Precision Engineering and Manufacturing - Green Technology, 5(1), 111-119.

Mithun, S. K., Umesh, S., and Pathan, R. (2013). "Conceptual design of motorcycle helmet to meet the requirement of thermal comfort, ergonomics and safety," SASTECH Journal 65(1), 65-71.

Mitra, B. C. (2014). "Environment friendly composite materials: Biocomposites and green composites," Defence Science Journal 64(3), 244-261. DOI: 10.14429/dsj.64.7323

Muhammad Huzaifah, M., Sapuan, S. M., Leman, Z., and Ishak, M. R. (2017). "Comparative study on chemical composition, physical, tensile, and thermal properties of sugar palm fiber (Arenga pinnata) obtained from different geographical locations," BioResources 12(4), 9366-9382. DOI: 10.15376/biores.12.4.9366-9382

Nelson, C. A. (1986). "A scoring model for flexible manufacturing systems project selection," European Journal of Operational Research 24(3), 346-359. DOI: 10.1016/0377-2217(86)90028-7

Pickering, K. L., Efendy, M. G. A., and Le, T. M. (2016). "A review of recent developments in natural fibre composites and their mechanical performance," Composites Part A: Applied Science and Manufacturing 83, 98-112. DOI: 10.1016/j.compositesa.2015.08.038

Pimenta, S., and Pinho, S. T. (2011). "Recycling carbon fibre reinforced polymers for structural applications: Technology review and market outlook," Waste Management 31(2), 378-392. DOI: 10.1016/j.wasman.2010.09.019

Pohekar, S. D. and Ramachandran, M. (2004). "Application of multi-criteria decision making to sustainable energy planning - A review," Renewable and Sustainable Energy Reviews 8(4), 365-381. DOI: 10.1016/j.rser.2003.12.007

Puglia, D., Biagiotti, J., and Kenny, J. M. (2005). "A review on natural fibre-based composites - Part II: Application of natural reinforcements in composite materials for automotive industry," Journal of Natural Fibers 1(3), 23-65. DOI: 10.1300/J395v01n03_03

Raja, T., Anand, P., Karthik, M., and Sundaraj, M. (2017). "Evaluation of mechanical properties of natural fibre reinforced composites - A review," International Journal of Mechanical Engineering and Technology 8(7), 915-924.

Saba, N., Jawaid, M., Sultan, M. T. H., and Alothman, O. Y. (2017). "Green biocomposites for structural applications," in: Green Biocomposites: Design and Applications ( $1^{\text {st }}$ ed.), M. Jawaid, M. S. Salit, and O. Y. Alothman (eds.), Springer, Cham, Switzerland, pp.1-27. DOI: 10.1007/978-3-319-49382-4_1

Sahu, P., and Gupta, M. K. (2020). "A review on the properties of natural fibres and its bio-composites: Effect of alkali treatment," Proceedings of the Institution of 
Mechanical Engineers, Part L: Journal of Materials: Design and Applications 234(1), 198-217. DOI: 10.1177/1464420719875163

Salit, M. S. (2014a). "Manufacturing techniques of tropical natural fibre composites," in: Tropical Natural Fibre Composites, Springer, The Gateway, Singapore, pp. 103-118. DOI: 10.1007/978-981-287-155-8_6

Salit, M. S. (2014b). "Tropical natural fibres and their properties," in: Tropical Natural Fibre Composites, Springer, The Gateway, Singapore, pp. 15-38. DOI: 10.1007/978981-287-155-8_2

Salwa, H. N., Sapuan, S. M., Mastura, M. T., and Zuhri, M. Y. M. (2019). “Analytic hierarchy process (AHP)-based materials selection system for natural fiber as reinforcement in biopolymer composites for food packaging," BioResources 14(4), 10014-10046. DOI: 10.15376/biores.14.4.10014-10046

Sanyang, M. L., Sapuan, S. M., Jawaid, M., Ishak, M. R., and Sahari, J. (2016). "Effect of sugar palm-derived cellulose reinforcement on the mechanical and water barrier properties of sugar palm starch biocomposite films," BioResources 11(2), 4134-4145. DOI: 10.15376/biores.11.2.4134-4145

Su, Y., Yang, B., Liu, J., Sun, B., Cao, C., Zou, X., Lutes, R., and He, Z. (2018). "Prospects for replacement of some plastics in packaging with lignocellulose materials: A brief review," BioResources 13(2), 4550-4576. DOI: 10.15376/biores.13.2.Su

Wang, P., Meng, P., Zhai, J., and Zhu, Z. (2013). "A hybrid method using experiment design and grey relational analysis for multiple criteria decision making problems," Knowledge-Based Systems 53, 100-107. DOI: 10.1016/j.knosys.2013.08.025

Wu, Y., Xia, C., Cai, L., Shi, S. Q., and Cheng, J. (2018). "Water-resistant hemp fiberreinforced composites: In-situ surface protection by polyethylene film," Industrial Crops and Products 112, 210-216. DOI: 10.1016/j.indcrop.2017.12.014

Yoon, K. P., and Hwang, C. (1995). Multiple Attribute Decision Making: An Introduction ( $1^{\text {st }}$ ed.), Sage Publications, Thousand Oaks, CA, USA.

Yurdakul, M., and Tansel, Y. (2009). "Application of correlation test to criteria selection for multi criteria decision making (MCDM) models," The International Journal of Advanced Manufacturing Technology 40(3), 403-412. DOI: 10.1007/s00170-0071324-1

Zakriya, M. and Ramakrishnan, G. (2021). Natural Fibre Composites: Manufacturing, Characterization, and Testing, CRC Press, Boca Raton, FL, USA.

Zwawi, M. (2021). "A review on natural fiber bio-composites, surface modifications and applications," Molecules 26(2), article no. 404. DOI: 10.3390/molecules26020404

Article submitted: September 29, 2021; Peer review completed: November 5, 2021; Revised version received: November 7, 2021; Accepted: November 8, 2021: Published: November 10, 2021.

DOI: 10.15376/biores.17.1.109-131 


\section{APPENDIX}

\section{Supplemental Material}

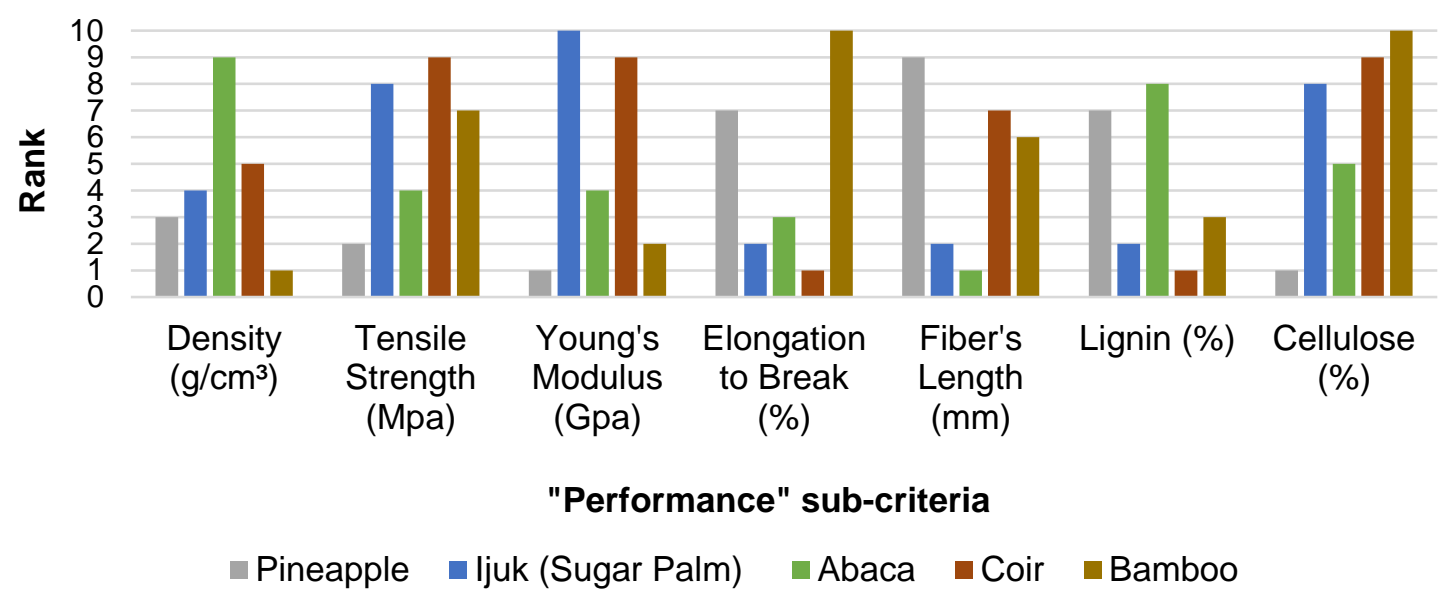

Fig. S1. Alternatives result for the five highest values of "Performance" criteria

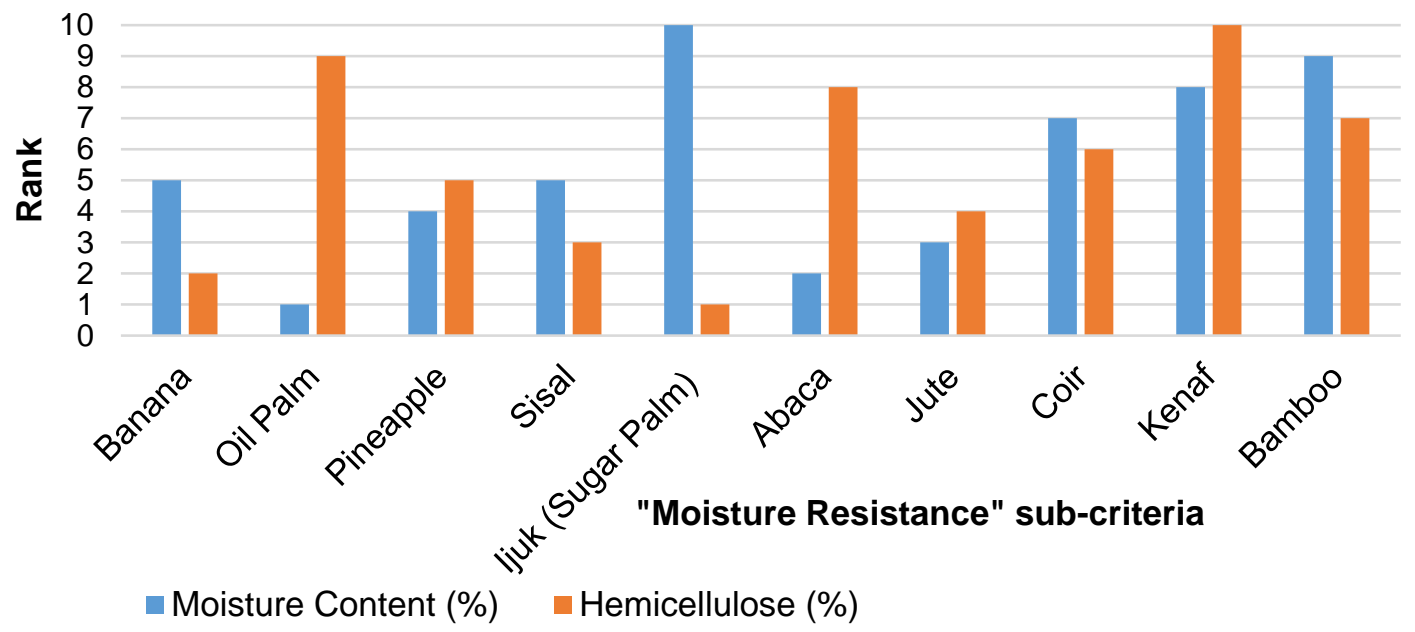

Fig. S2. Alternatives result for the five highest values of "Moisture Resistance" criteria

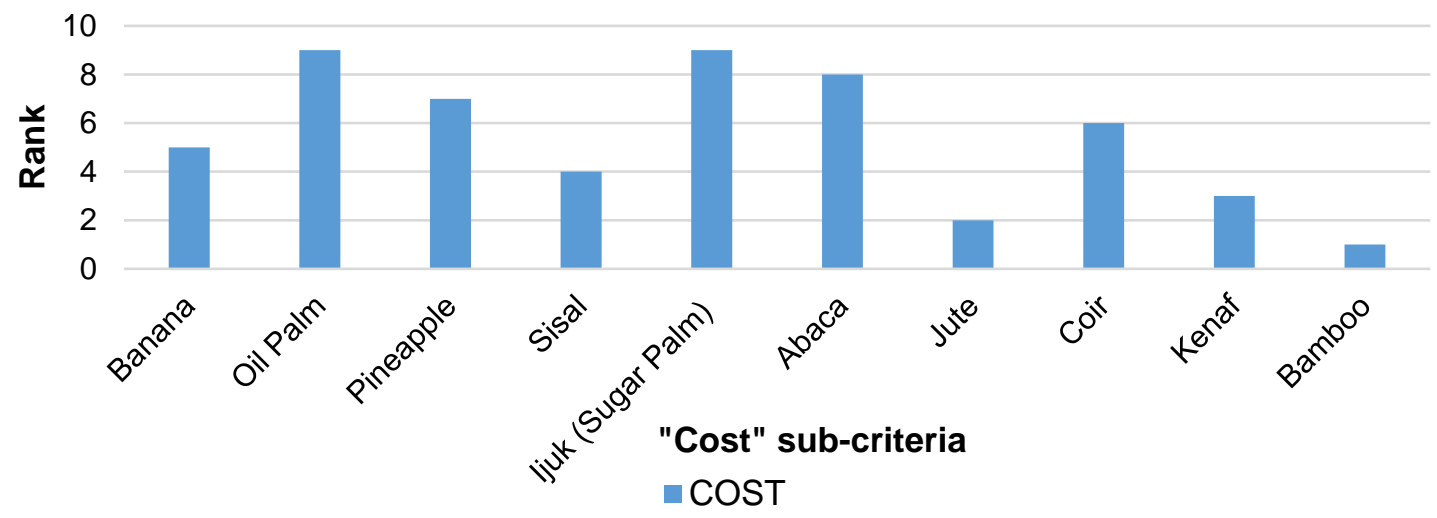

Fig. S3. Alternatives result for the five highest values of "Cost" criteria 